\title{
As Condiç̃es Políticas e os Fundamentos Teológicos da Nova Direita Cristã no Brasil
}

Ole Jakob Løland ${ }^{a}$

Resumo: Jair Messias Bolsonaro venceu as eleições presidenciais de 2018 no Brasil com o apoio de quase $70 \%$ dos evangélicos e cerca de $50 \%$ dos católicos do país. Este artigo tem como objetivo explorar algumas das teologias políticas e influentes que são disseminadas por alguns dos aliados religiosos de Bolsonaro, construindo três tipologias teológicas: Sobrenaturalismo neoliberal, dualismo apocalíptico e neoconservadorismo católico. Sobrenaturalismo neoliberal, dualismo apocalíptico e neoconservadorismo católico. Além disso, argumentamos que a Nova Direita Cristã no Brasil é comparável ao fenômeno 'the Christian Right', típico dos Estados Unidos, devido às condicões políticas e bandeiras morais semelhantes. A ascensão de Boĺsonaro e a virada para a direita na política brasileira podem ser em parte entendidas como um efeito dessa nova aliança política legitimado de três forças cristãs politicamente conservadoras e suas teologias: o pentecostalismo tradicional, o neopentecostalismo e o catolicismo neoconservador. Embora haja traços autoritários dentro do que pode ser chamado a Nova Direita Cristã do Brasil, também se pode reconhecer esse fenômeno político como uma contribuição à democracia brasileira.

Palavras-chave: Religião brasileira, Secularismo, Evangelho da prosperidade, Neoconservadorismo católico, Pentecostalismo, Teologia política.

Em seu minucioso levantamento do papel político das igrejas cristãs nos recentes processos eleitorais recentes no Brasil, a cientista política Amy Erica Smith observa que a campanha do clero evangélico provou ser relativamente malsucedida (2019:114). A principal causa

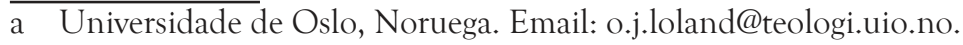


disso tem sido a falta de coordenação dentro da liderança evangélica. Eles não escolheram o mesmo candidato presidencial nem o mesmo partido político para apoiar (Smith 2019:114). As descobertas de Smith foram baseadas em uma análise detalhada dos anos anteriores a 2018, pouco antes de o Brasil testemunhar algo novo na interação entre religião e política. A eleição de Jair Bolsonaro em 28 de outubro de 2018 foi a expressão do que uma direita cristã unificada poderia alcançar. Indiscutivelmente, os dois líderes evangélicos mais destacados, Silas Malafaia, da Assembleia de Deus (AD) e Edir Macedo, da Igreja Universal do Reino de Deus (IURD), pela primeira vez, apoiaram um único candidato; o direitista Jair Bolsonaro. Sua vitória foi histórica, por ser a expressão mais poderosa da fortalecida direita cristã no Brasil. Além disso, a frente evangélica no Congresso, comumente conhecida no Brasil como bancada evangélica, havia consolidado seu poder com 84 dos 513 deputados do Congresso e, portanto, era maior, enquanto bloco, do que qualquer partido político. Além disso, foram eleitos 7 senadores, alinhados ao mesmo bloco (Almeida 2019:202). Quais são os fundamentos políticos e teológicos deste vibrante e vigoroso aliado da nova direita política na maior economia da América Latina? Pode ser comparada à direita cristã nos Estados Unidos, e essa sua correspondente no Brasil representa uma ameaça à democracia?

A teologia política pode ser entendida como inserida na relação instável e mutável entre comunidades políticas e ordens religiosas ou visões de mundo (de Vries 2006:25). Estudar teologias operantes e influentes na política significa, em outras palavras, prestar atenção especial às formas específicas pelas quais o poder político é construído e legitimado recorrendo a noções do divino. O debate sobre os traços potencialmente autoritários e não democráticos da religião politizada é antigo (de Vries 2006; Gentile 2006). Também tem sido debatido, na literatura acadêmica, se deve-se perceber a busca dos evangélicos por poder político na América Latina através do espelho do movimento da direita cristã nos Estados Unidos (Freston 2013; 
Lehmann 2013; Levine 2012; Shah 2004). Ambas as questões, com a ascensão de Bolsonaro, ganharam nova atualidade nas pesquisas sobre religião e política no Brasil (Almeida 2020; Burity 2020; Carranza 2020; Abranches et al 2019). Poucas obras, no entanto, enfocaram a natureza especificamente teológica do discurso dos aliados religiosos de Bolsonaro.

\section{A nova era política em um cenário religioso em mudança}

A posse de Jair Messias Bolsonaro como presidente do Brasil, em 10 de janeiro de 2019, marcou uma nova época política. Durante a cerimônia no Congresso brasileiro, o recém-eleito presidente afirmou que estava em 'missão' de restaurar a pátria e libertá-la da corrupção, do crime, da irresponsabilidade econômica e do que chamou de 'submissão ideológica' (Bolsonaro 2019). Bolsonaro também proclamou que 'a ideologia de gênero' deveria ser combatida em um Brasil que viria a ser livre de ideologias de qualquer tipo, em defesa da família e da tradição judaico-cristã. A ideia de uma ‘ideologia de gênero’ não era exclusiva de Bolsonaro. Esse 'outsider' político havia se apropriado do discurso divulgado por padres católicos e, também, por pastores protestantes em seu país. Bolsonaro não ganhou o apoio uníssono de todos os líderes cristãos, pois uma minoria considerável deles resistiu ativamente à sua campanha para a presidência. Mesmo assim, Bolsonaro havia investido retoricamente e estrategicamente num tropo teológico caro a muitos brasileiros cristãos, que votaram contra políticas que acreditavam serem capazes de arruinar a família nuclear cristã, educar crianças brasileiras em se tornarem homossexuais ou tornar ilegal as declarações, baseadas em convicções religiosas, de que a prática de homossexual é um pecado o que, consequentemente, limitaria sua liberdade religiosa. Em um país onde a legalização do aborto foi considerada politicamente improvável de ser aprovada pela maioria dos legisladores eleitos, pastores e políticos sabiam que uma batalha política mais decisiva tinha que ser travada nas áreas de gênero e sexualidade. Desse modo, esses tópicos foram trazidos para o centro da 
guerra cultural do Brasil. No entanto, a iniciativa do governo, de 2005, para revisar as leis sobre o aborto, no Código Penal, serviu, junto com outras propostas do governo, como o programa 'Brasil sem Homofobia', como oportunidades para que os conservadores religiosos mobilizassem os membros de suas congregações para participarem de atividades políticas, em reuniões, campanhas e marchas (Machado 2012).

Originalmente um grupo mais diverso, essas forças religiosas reacionárias têm, ao longo dos anos, coordenado seu trabalho para fortalecer sua influência, conforme manifestado no Bloco evangélico no Congresso (A Bancada Evangélica). Um exemplo interessante é a visão evangélica dissidente sobre o aborto que o fundador e bispo neopentecostal da IURD defende. Enquanto Edir Macedo clama por uma política de aborto pró-escolha, seus seguidores mantêm, como o resto da população brasileira, um ponto de vista restritivo pró-vida. ${ }^{1}$ Provavelmente em função de um cálculo político, os candidatos vinculados a IURD consistentemente ignoram a visão de seu líder e fazem campanha com uma postura pró-vida (Smith 2019:67). Com políticas que poderiam apelar aos meios pentecostais e evangélicos, de forma mais ampla, até mesmo aos católicos, eles contribuíram para uma frente cristã mais unificada, que opôs princípios supostamente religiosos às ideologias seculares.

Em seu discurso de posse, Bolsonaro também prometeu que seu governo estaria 'maculando a classe política' e colocaria o Brasil em primeiro lugar (Brasil acima de tudo!). Sua 'missão' poderia ser realizada graças à intervenção divina, já que sua vida foi poupada por 'um milagre' no hospital.

O contraste entre a posse do período presidencial de Bolsonaro e a era iniciada com a posse de Luiz Inácio Lula da Silva como novo presidente do país em $1^{\circ}$ de janeiro de 2003 foi impressionante (Silva 2003). Lula também agradeceu a Deus, mas não por ter milagrosamente salvo sua vida. O esquerdista agradeceu a Deus por tê-lo levado à posição de 'servidor público número um' do Brasil. Enquanto 
Lula invocou Deus duas vezes em seu discurso inaugural, Bolsonaro mencionou a divindade seis vezes em um discurso consideravelmente mais curto. Enquanto Bolsonaro acabaria com a classe política, Lula prometeu acabar com a fome. E ao contrário de Bolsonaro, Lula não prometeu erradicar ideologias, mas fazer da erradicação da fome uma causa de todo brasileiro, independentemente de sua ideologia, como se reconhecesse e até valorizasse a diversidade política. Notavelmente, Lula imaginou o Brasil como uma nação pluralista e diversa, com um lugar especial para as comunidades indígenas e negras. Em suma, a fala de Lula foi um discurso cerimonial menos abertamente religioso, com ênfase liberal na diversidade cultural. Não era radicalmente secularista. Afinal, Deus foi apresentado como parte da base do mandato de Lula como líder da nação.

No entanto, após assumir as Relações Exteriores, Ernesto Araújo declarou em sua 'Carta de Brasília' que o 'marxismo cultural' havia sido derrotado com a vitória de Bolsonaro, e proclamou: "A última barreira foi rompida: nós agora podemos falar de Deus em público. Quem poderia imaginar uma coisa dessas?" (Araújo 2019). O membro do gabinete de Bolsonaro argumentou como se não houvesse espaço para falar de Deus na política brasileira, devido ao 'controle do pensamento' do Partido dos Trabalhadores e da elite. Em outras palavras, ele comemorou a vitória sobre uma imaginária intolerância secularista de esquerda. Em seu discurso de celebração do novo ambiente cívico, liberado da censura secularista da esquerda, o ministro não mencionou que a separação entre Igreja e Estado no Brasil tem sido aplicada desde a Constituição de 1891 da Primeira República, sem a exclusão da religião da vida política. Além disso, o secularismo brasileiro, ao contrário dos casos de México ou Uruguai, nunca resultou num movimento secularista radical (Mariano 2011).

Com a liberdade religiosa declarada pela República de 1891, os imigrantes protestantes puderam fundar Igrejas Luteranas, Presbiterianas, Batistas e Congregacionais. Eles mantiveram um perfil discreto e apenas com a estratégia pelos pentecostais de um partidarismo 
religioso ('irmão vota no irmão'), após o retorno da democracia em 1985, foi que os protestantes ganharam considerável influência política, na forma de algumas cadeiras no Congresso (Mariano \& Oro 2017). Nas últimas décadas, no entanto, a mobilização eleitoral evangélica resultou em um número crescente de políticos eleitos, de forma análoga ao crescimento geral da população evangélica. As eleições do pentecostal Eduardo Cunha, como presidente da Câmara dos Deputados em 2015, bem como a eleição do bispo da IURD Marcelo Crivella, como prefeito nas eleições municipais do Rio de Janeiro de 2016, constituem marcos políticos para a política evangélica no Brasil (Lacerda 2018). Além disso, em abril do mesmo ano, políticos da frente evangélica se notabilizaram ao defender seu voto a favor do impeachment da presidente de esquerda Dilma Rousseff com declarações de voto tais como 'para Deus' e 'para os evangélicos' (Martins 2016).

O termo 'evangélico' é usado neste artigo para designar os segmentos sociais de brasileiros que se autodenominam como tal. Abrange os cristãos carismáticos nas principais denominações, bem como os protestantes históricos que chegaram no século XIX. Refere-se principalmente, entretanto, ao grupo vagamente definido de pentecostais, do tipo originalmente clássico de $\mathrm{AD}$ ao neopentecostal representado pela IURD. ${ }^{2} \mathrm{O}$ evangelicalismo carismático é atualmente a tendência dominante do protestantismo global e o Brasil é um de seus epicentros globais. Tem crescido constantemente em toda a América Latina, nas últimas décadas, mas não se traduziu em representação política em todos os contextos nacionais da região. No Brasil, tem uma representação maior do que outras minorias religiosas, por exemplo, religiões afro-brasileiras. Se essas igrejas não tivessem desenvolvido a estratégia de apoiar ativamente os candidatos de suas próprias congregações, seus adeptos provavelmente teriam sido subrepresentados nas legislaturas brasileiras.

Como evidenciado em seu discurso de posse, Bolsonaro investiu pesadamente na ideia da ameaça da 'ideologia de gênero' estrangeira e alienante para a nação brasileira. Ele provavelmente ganhou mui- 
to com isso. De acordo com o instituto de pesquisas Datafolha, os evangélicos representaram 31\% do eleitorado, refletindo um rápido crescimento dos 22\% apurados no Censo de 2010 (Schmidt e Engler 2017). Quase 70\% deles relataram que pretendiam votar em Bolsonaro no segundo e decisivo turno, enquanto cerca de metade dos católicos disse o mesmo (Datafolha 2018). Metade dos católicos declarou apoio ao esquerdista Fernando Haddad. Isso é indicativo de uma divisão política mais profunda entre os católicos, bem como de um legado persistente de uma esquerda católica no Brasil. Fundado por grupos de oposição ao regime militar (1964-1985) na época em que a Igreja Católica figurava como a instituição central de resistência ao regime não-democrático, o Partido dos Trabalhadores (PT) foi, desde seu início em 1980, povoado por ativistas católicos. Os laços sociais entre as comunidades de base católica e o partido foram particularmente fortes na década de 1980, quando os militantes do PT receberam grande parte sua educação política do meio eclesial inspirado na Teologia da Libertação. Ativistas de esquerda, de sindicatos e organizações religiosas, eram a base social primária do partido em 1990 (Follmann 2000). O Partido dos Trabalhadores ganhou poder presidencial em 2003 e formou uma coalizão que incluía até mesmo um partido de direita. Muitos ativistas de esquerda se retiraram do partido, particularmente após o primeiro grande escândalo de corrupção ('Mensalão') em 2004 5 que envolveu o partido (Mainwaring 2018). Ele foi gradualmente perdendo sua antiga base nos movimentos sociais de esquerda, incluindo ramos das comunidades de base. Mesmo assim, Lula se tornou um presidente notavelmente popular e foi reeleito em $2006 \mathrm{com}$ apoio considerável dos eleitores evangélicos. Os eleitores evangélicos foram mais rápidos em retirar seu apoio ao Partido dos Trabalhadores do que os católicos e adeptos de outras religiões ou não-religião (Smith 2019: 19), mas ainda constituíam uma parcela considerável do eleitorado que votou no segundo mandato de Lula e no de sua candidata à sucessão presidencial, pelo Partido dos Trabalhadores, Dilma Rousseff, em 2010 e 2014. Embora a população evangélica 
fosse menos disposta no seu apoio, os que disseram que votariam em Dilma ainda eram maioria dentro desse grupo religioso. Se Lula tivesse sido autorizado a se candidatar à presidência em 2018, as pesquisas indicaram que ele poderia ter vencido, também com votos significativos de cristãos evangélicos, talvez até mesmo apoiado pela instituição evangélica que possui a máquina eleitoral, indiscutivelmente, mais eficaz: a IURD. Embora a IURD fizesse campanha abertamente contra Lula, nas eleições de 1989, e o demonizasse implicitamente em 1994 (Corten 1996:108; Freston 2001:30), ela o favoreceu, bem como os candidatos presidenciais do Partido dos Trabalhadores de 2002 em diante. Eles parecem aderir ao candidato vitorioso e foi apenas oito dias antes do primeiro turno em 2018 que o seu bispo Edir Macedo declarou abertamente seu apoio a Bolsonaro (Balloussier 2018b). Isso levanta a questão de se a teologia tem algum peso significativo nessa igreja neopentecostal ou se os interesses estratégicos projetados para maximizar o resultado eleitoral para seus próprios agentes políticos, e a sua influência política mais ampla, são mais determinantes.

Ao considerar o imenso apoio a Bolsonaro, dado pelos eleitores evangélicos, é fundamental entender que, se Lula não tivesse sido preso, teria introduzido uma lógica política totalmente diferente para o processo eleitoral em 2018, com um número de eleitores evangélicos maior do que nunca na história do Brasil. Em outras palavras, o candidato que capitaliza as questões teológicas centrais dos pastores, como gênero e sexualidade, não é necessariamente aquele que obtém a vitória. Existem outros fatores, mais decisivos do que a religião, mesmo em uma democracia religiosamente vibrante como o Brasil, onde quase metade da população relata frequentar um serviço religioso pelo menos uma vez por semana (Pew 2014). As igrejas são, em outras palavras, algumas das arenas mais centrais para a socialização para os cidadãos brasileiros e o tipo de teologia política a que estão expostos é potencialmente influente para o resultado das eleições. Considerar que os brasileiros relatam ter confiança mínima nos partidos políticos e consideram a Igreja Católica como a mais confiável, apenas supera- 
da pelas Forças Armadas (Paz 2018), significa que a religião cristã persiste como fonte de capital moral e, também, de legitimidade política.

\section{A direita cristã brasileira - paralelos e condições}

O sociólogo brasileiro Paul Freston alertou, em uma publicação de 2013, contra a visão do pentecostalismo do Terceiro Mundo 'pelas lentes da direita religiosa americana' e, assim, a redução do pentecostalismo global a 'uma extensão do soft power americano'. Ele se referiu a dados de 2006 que demonstram como o apoio dos pentecostais latino-americanos à guerra dos EUA contra o terrorismo e o sionismo cristão, ou o apoio às políticas do Estado de Israel, foram menores do que entre os pentecostais norte-americanos, como se isso mostrasse que guerras culturais nos EUA não foram reproduzidas na América Latina (Freston 2013). David Lehmann concordou com a opinião de Freston (Lehmann 2013).

$\mathrm{O}$ argumento que sustenta um paralelo entre a direita cristã nos Estados Unidos e no Brasil não reivindica uma simples reprodução das guerras culturais norte-americanas na América Latina. Busca, antes, apontar a semelhança em certos aspectos, sem reduzir as dimensões singulares da dinâmica cultural brasileira a um reflexo de eventos que acontecem em outros lugares. Podemos dar sentido ao caso brasileiro por meio de algum grau de comparação, embora levando a sério a ideia de que múltiplas teologias e práticas do cristianismo estão sendo difundidas globalmente e, ao mesmo tempo, adaptadas aos contextos locais. Além disso, desde a publicação de Freston em 2013, uma mudança considerável para a direita ocorreu entre os eleitores evangélicos brasileiros. Os eleitores pentecostais citados por Freston, por seu baixo apoio ao sionismo cristão, escolheram um presidente que quase reverteu a política externa do Brasil em relação aos palestinos, alegando que "a Palestina não é um país, então não deveria haver embaixada aqui” (BBC 2018). À luz das recentes mudanças políticas na política brasileira, o alerta de Freston parece ter perdido alguma força argumentativa desde sua publicação. 
Semelhante à dinâmica política nos Estados Unidos, a proliferação de visões de mundo concorrentes das igrejas impulsiona as guerras culturais fixadas em tópicos como família, saúde reprodutiva e sexualidade que tornam as divisões políticas mais visíveis ou criam polarização política. Desde que o Partido dos Trabalhadores lançou, em 2004, iniciativas de Direitos Humanos, como o programa 'Brasil sem Homofobia', vários grupos religiosos têm reagido de maneiras que emitem sinais de que consideram a visão de mundo de seus adversários políticos como reciprocamente incompatível com a sua. Daí a adequação do termo "guerra cultural" (Smith 2019:4). Uma decisão histórica, que confirmou a existência de uma ordem imoral, desprovida de valores cristãos, representada pelas decisões tomadas pelo Estado liderado pelo Partido dos Trabalhadores, foi a legalização do casamento entre pessoas do mesmo sexo, manifestada em decisões do Superior Tribunal Federal, em 2011 e 2013. De um ponto de vista religioso, essa decisão poderia testar a confiança dos conservadores religiosos na democracia, ou seja, sua tolerância a uma ordem que legalmente abrisse espaço para práticas consideradas pecaminosas de acordo com sua fé. Isso cria condições para uma suspeição em relação ao Estado, mas há uma questão em aberto, que é se essa suspeita fornece opiniões políticas que clamam por um Estado mínimo ou para a conquista do Estado, a fim de cristianizá-lo, independentemente de seu tamanho. O resultado, no entanto, pode levar a políticas neoliberais e ao encolhimento do setor público (cortes no programa Bolsa Família etc.), já que as questões da guerra cultural brasileira são, em suma, um dos motores do movimento eleitoral em direção a direita política.

As associações que o termo 'Direita Cristã' atribui ao conhecido ativismo político de vários grupos cristãos nos Estados Unidos, a partir do final dos anos 1970, ajudam a indicar algumas características de sua contraparte brasileira. Em primeiro lugar, semelhante ao caso dos Estados Unidos, o fenômeno brasileiro emergiu de grupos evangélicos principalmente protestantes que, nas lutas típicas contra a liberalização das leis sobre o aborto e contra o reconhecimento legal 
do casamento gay pelo Estado, têm interesses estratégicos em comum com certos grupos católicos, apesar da rivalidade religiosa e diferenças ideológicas em outras questões centrais para sua confissão particular. O conservadorismo católico certamente antecede o evangelicalismo reacionário, mas pode ser renovado por ele. Essa mobilização política é, em alto grau, percebida por esses ativistas e grupos como uma batalha contra uma visão de mundo não religiosa, incompatível com a sua. Investe-se, retorica e politicamente, na oposição imaginada entre religião e laicidade. Em segundo lugar, como nos Estados Unidos, essa guerra cultural contribui para a polarização social e política que se origina nas fixações desses grupos em domínios políticos que não estão intrinsecamente ligados a outros tópicos políticos, como ecologia, economia de mercado ou redistribuição econômica. A mobilização dos grupos cristãos em torno de um número limitado de questões, às vezes transformando os cidadãos em eleitores de uma só questão (Millies 2018), efetivamente move grupos de eleitores com motivação religiosa em direção à direita política. Terceiro, esses grupos brasileiros também podem ser corretamente considerados um paralelo ou uma duplicata da direita cristã nos Estados Unidos, com base em condições políticas comparáveis quando esses atores religiosos tentam ganhar influência, e até mesmo domínio, do cenário político.

Tanto nos Estados Unidos quanto no Brasil, esses grupos prosperam em climas políticos condicionados por Estados secularistas passivos, que são constitucionalmente limitados pelo princípio da separação entre Estado e religião e, portanto, não privilegiam oficialmente uma confissão em particular. Ilustrativamente, a educação católica é legalmente proibida nas escolas públicas brasileiras. ${ }^{3}$ Oficialmente, esses Estados se retiram de uma esfera política que deve ser preenchida ou conquistada pela religião se a política seria explicitamente ancorada e legitimada por meio da religião. Tanto o Estado Federal brasileiro quanto o estadunidense podem ser defendidos como exemplos de secularismo passivo (Kuru 2007). As poucas barreiras impostas aos agentes que desejam entrar na economia religiosa, relativamente des- 
regulada desses países, combinadas com algumas restrições à capacidade dos grupos religiosos de fazer campanha para partidos políticos e candidatos, são responsáveis por isso. Amy Erica Smith considera os regulamentos legais contra certas formas de campanhas eleitorais empreendidas por igrejas, como uma analogia à emenda Johnson de 1954, que proíbe organizações sem fins lucrativos isentas de impostos, como, por exemplo, igrejas, de fazer campanha em nome de políticos ou partidos (Smith 2019:86).

Embora o modelo de Estado secularista nos dois países imponha condições semelhantes para a direita cristã, o sistema partidário no qual essas duas vertentes ou movimentos buscam influência é muito diferente. Enquanto a competição eleitoral nos Estados Unidos ocorre dentro de um dos sistemas bipartidários mais rígidos do mundo (Taylor 2017:722), a luta democrática por posições políticas no Brasil ocorre na base de um sistema altamente fragmentado com 30 partidos representados na Câmara dos deputados do Congresso. Curiosamente, o aumento da representação política de segmentos minoritários evangélicos da população se desenvolveu ao lado dessa combinação de fragmentação parcial e institucionalização simultânea do sistema partidário. Ao contrário dos países da América Latina onde os sistemas partidários sofreram desinstitucionalização ou colapso, no Brasil esse sistema se tornou cada vez mais institucionalizado e a competição eleitoral foi mais estável de 1994 até 2014 (Mainwaring 2018:195-96), em parte graças ao sucesso do Partido dos Trabalhadores de Lula (2018:190).

Embora alguns políticos evangélicos tenham conquistado cargos em alguns dos principais partidos, como a pentecostal Benedita da Silva, que ocupou o cargo de deputada federal pelo Partido dos Trabalhadores já em $1986^{4}$, um número desproporcionalmente alto de deputados da Frente Evangélica representa partidos menores, oriundos de regiões de grande expressão populacional, como São Paulo. Isso provavelmente reflete uma estratégia de maximizar o poder eleitoral evangélico com base no cálculo e na experiência histórica (Reich $\&$ dos Santos 2013). Ser evangélico não traz benefício eleitoral para 
um candidato em comparação com um não evangélico, embora ser evangélico permite a esses candidatos a possibilidade de ocupar cadeiras para as quais não teriam recursos para fazer campanha sem o patrocínio de igrejas e sua infraestrutura (rádios, canais de TV, igrejas como arenas políticas) (Lacerda 2018:32). Uma vez que esses políticos evangélicos também tendem a mudar de partido com mais frequência do que os deputados não religiosos, eles contribuíram menos para a mencionada institucionalização do sistema partidário.

O efeito negativo sobre o voto ao se colocar como um candidato evangélico, no entanto, aponta para algumas das limitações da influência política das teologias por trás do fortalecimento da direita cristã no Brasil. As ideias teológicas são importantes. Mesmo assim, seu poder sobre o coração e a mente dos eleitores brasileiros é limitado por uma série de fatores, uma vez que o eleitorado e seus deputados não cumprem apenas o que seus líderes religiosos lhes dizem para fazer. Não existe um efeito de difusão simples das ideias teológicas sobre as realidades políticas. $\mathrm{O}$ cálculo de 20 por cento de fidelidade que os dirigentes da IURD projetaram é um indicativo da probabilidade de tal efeito vertical sobre os adeptos das igrejas cristãs. Além disso, esta é sem dúvida a igreja mais eficaz em termos de mobilizar seus adeptos para votar em candidatos específicos (Smith 2019:122).

Mesmo as pessoas mais religiosamente comprometidas, em termos de comparecimento às reuniões cristãs, que potencialmente podem ser preenchidas com discursos políticos, são influenciadas por uma série de outras forças persuasivas da sociedade em tempos de eleições. E nem todos os líderes da igreja endossam candidatos específicos. Frequentemente, eles se limitam a declarações gerais sobre a escolha de um candidato que faz a vontade de Deus ou limitam sua pregação a tópicos como aborto, gênero ou cuidado com os pobres. Além disso, a fim de salvaguardar seus interesses corporativos, uma igreja como a IURD pode se concentrar exclusivamente nas eleições legislativas (Smith 2019:118), deixando a questão de quem deve ser o presidente para seus adeptos decidirem. 
Em outras palavras, medir o efeito teológico exato nas urnas é uma tarefa árdua, para não dizer impossível. No entanto, existem certas teologias que se mostraram particularmente úteis para a direita cristã no Brasil e que, portanto, exercem considerável influência sobre a política do país, manifestada com força na eleição de Bolsonaro e no sucesso eleitoral da Frente Evangélica no Congresso brasileiro. Primeiro, há o que pode ser detectado como um sobrenaturalismo neoliberal no caso do neopentecostalismo. Segundo, há um dualismo apocalíptico evidenciado em formas distintas e mais tradicionais de pentecostalismos politicamente comprometidos. Terceiro, as expressões neoconservadoras do catolicismo ganharam mais terreno na última década no Brasil, não apenas por meio de sua hostilidade teologicamente fundamentada ao esquerdismo político.

Sem assumir que os três são casos isolados que existem em formas puras, essas teologias podem ser discernidas como tipologias que podem ser conjecturadas aqui, sem negligenciar que as teologias operantes na pregação e nas práticas das igrejas no Brasil têm múltiplas formas que atestam a imensa diversidade do cristianismo no país e em toda a região da América Latina. Embora, por exemplo, a teologia da prosperidade seja um dos principais objetos de desacordo entre o clero de várias denominações cristãs no Brasil (2019: 65), sua difusão não pode ser estritamente limitada ao neopentecostalismo.

\section{Sobrenaturalismo neoliberal: neopentecostalismo}

Milhões de brasileiros aderem às várias igrejas neopentecostais, das quais a IURD é indiscutivelmente a mais visível e, também, poderosa, principalmente por sua propriedade da emissora de televisão Rede Record, adquirida em 1990 (a primeira estação de TV a entrevistar Bolsonaro depois de sua vitória eleitoral) (Birman \& Lehmann 1999). Seu fundador, Edir Macedo, lidera a igreja desde a década de 1970. Embora Macedo tenha endossado a candidatura de Bolsonaro, alguns dias antes da eleição em 2018, a influência da teologia da IURD é de um tipo mais indireto; a igreja torna o eleitor receptivo à 
direita política por meio da cosmovisão que dissemina através de sua adaptação da teologia da prosperidade norte-americana. Nas décadas de 1940 e 1950, os evangelistas pentecostais começaram a explicar aos seus seguidores como a riqueza, o capitalismo e a devoção ao Deus cristão estavam inter-relacionados (Bowler 2013). Por meio da entrega e da confiança em Deus, o crente pode alcançar a benção divina em formas materiais de riqueza e saúde, aqui e agora, na terra (Garrard -Burnett 2013). O capitalismo moderno tornou-se, assim, a estrutura normalizada na qual o divino opera e o evangelho da prosperidade alivia o crente de qualquer suspeita de que o próprio sistema econômico era contrário à vontade e ordem divinas neste mundo. Nessa visão teológica do mundo, o sucesso econômico dos negócios empreendedores está longe de ser um resultado moralmente problemático da exploração econômica. É uma manifestação da confiança exemplar dos crentes em Deus. Os benefícios da economia de mercado não são totalmente transparentes para a racionalidade humana, uma vez que forças sobrenaturais operam dentro dela. $\mathrm{O}$ intelecto que impede o ser humano de reconhecer essas bençãos divinas, recebidas na esfera financeira, deve ser sacrificado para se atingir uma fé cristã real e ativa, segundo Edir Macedo. Caso contrário, ficaremos sujeitos às forças do diabo na guerra espiritual neste mundo.

$\mathrm{Na}$ IURD, essa naturalização das bençãos divinas do livre mercado é associada a uma inovação ritual que explora formas pré-institucionais de religião encontradas em formas heterogêneas do catolicismo popular (Løland 2015). Por meio da oração, bem como do uso ritualístico adequado de objetos religiosos, uma prosperidade milagrosa pode ser alcançada imediatamente. Não há necessidade de planejamento social de longo prazo ou análise política, pois tudo é possível, aqui e agora, para o indivíduo que tem fé em Deus.

Entre estas práticas religiosas está o sacrifício na forma de dinheiro, um objeto em que se investe fortemente como um meio de prosperidade divina. Se você tiver uma fé verdadeira, receberá o que paga por meio de benefícios milagrosos. Essa lógica teológica torna 
supérflua a solidariedade redistributiva, uma vez que não há escassez de recursos neste universo da teologia da prosperidade. Além disso, fornece uma teodiceia do sofrimento neste mundo que efetivamente deixa irrelevantes as análises de complexos processos sociais, econômicos e políticos. Estes não são nada complexos, na visão teológica de Macedo:

"É impossível para o ofertante não ter retorno espiritual e financeiro quando a oferta está de acordo com a vontade de Deus. Acredito que os cristãos, em sua maioria vivem uma vida na fronteira da pobreza e da miséria porque suas ofertas demonstraram a falta de amor, temor e respeito por Deus” (Macedo, citado em Stålsett 2006:205).

Desse modo, a miséria dos brasileiros mais pobres se apresenta como consequência direta da falta de fé verdadeira. É necessário oferecer dinheiro à igreja, até porque este constitui um artigo de fé para este grupo (Garrard-Burnett 2013:29). Em suma, a verdadeira crença torna-se alcançável através da compra de bens salvíficos na igreja que estão intimamente ligados às virtudes capitalistas da modernidade tardia de consumismo e individualismo (Mora 2008).

As forças sobrenaturais que são dramatizadas nas curas e exorcismos encenados nos serviços neopentecostais, encantam a racionalidade desencantada da economia de mercado. Além disso, esse encantamento também é representado na visão teológica da política, onde se supõe que as mesmas forças deverão estar agindo, no sentido direto da palavra. O próprio demônio pode estar presente no Congresso Nacional ou alguns políticos podem estar possuídos por espíritos demoníacos, conforme pregações na igreja (Oro 2003). Essa espiritualização do político também contribui para o deslocamento de explicações não religiosas dos males sociais. Como escreveu o bispo Guaracy Santos, cerca de duas semanas antes da vitória de Bolsonaro: por que existem tantos políticos corruptos e há tanta pobreza extrema? "O problema é totalmente espiritual”, assegurou o líder religioso da IURD (Santos 2018). Então, de onde vem a aliança com pentecostais mais conservadores, rivais no mercado religioso? 
Uma racionalidade amoral é inerente ao neoliberalismo, ao nível dos fins e dos meios. Isso não o torna incompatível com a teologia da prosperidade neopentecostal, uma vez que a lógica teológica, com seus circuitos de intercâmbio entre as forças sobrenaturais e a esfera natural do ser humano, não está vinculada a uma moral específica. Esta é uma lógica teológica elástica, que permite ao bispo ou pastor neopentecostal sancionar ou não um determinado comportamento moral do crente beneficiário da prosperidade. A mencionada visão liberal do bispo Macedo sobre o aborto é um indício da ruptura maior do neopentecostalismo com o conservadorismo moral do pentecostalismo mais tradicional, que tem raízes mais profundas nas formas clássicas no seu período inicial no Brasil. Tal se encontra lado ao lado com a polemica de Macedo contra o que ele considerou ser a 'política do kit gay' de Fernando Haddad.

Com interesses estratégicos nos governos liderados pelo Partido dos Trabalhadores, de 2003 a 2016, a IURD não esteve na vanguarda da guerra cultural nas últimas décadas. Uma indicação disso é o perfil político relativamente baixo do blog e da conta do Twitter de Edir Macedo. Mas essa estratégia também tem raízes teológicas na liberalização das normas comportamentais (Mariano 1999). Em vez de ser o principal catalisador da guerra cultural da direita cristã, essa igreja neopentecostal justifica e naturaliza a sobreposição do conservadorismo moral com o neoliberalismo que, no início, são duas racionalidades distintas (Brown 2006). Em suma, o sobrenaturalismo neoliberal está predisposto a servir ao apoio tácito do direito cristão à liberalização da economia de mercado, contornando questões de redistribuição econômica e direitos dos trabalhadores. A mão invisível do mercado vem a ser nada menos do que a mão de Deus.

\section{Dualismo apocalíptico: pentecostalismo tradicional}

Em tensão, mas também com uma certa sobreposição ao sobrenaturalismo neoliberal, está o que pode ser denominado 'dualismo apocalíptico'. Embora o evangelho da prosperidade sirva como subcorrente 
do discurso político oficial, há uma espiritualização igualmente dualista da política no pentecostalismo brasileiro que é explícita e sem reservas em seu endosso a candidatos políticos. Enquanto o neopentecostalismo prega tipicamente que a prosperidade divina é alcançável com fé suficiente no presente, algumas das formas mais tradicionais de pentecostalismo são mais direcionadas para expectativas futuras e realidades celestiais. A AD é um exemplo desse pentecostalismo tradicional, sendo essa a denominação de igrejas que reúne o maior número de pentecostais do Brasil. Alguns desses crentes, com orientação mais apocalíptica, estão esperando uma mudança decisiva dos assuntos terrenos, na expectativa da segunda vinda de Jesus, e essa dimensão temporal do apocalipsismo frequentemente leva a interpretações teológicas da história humana. Amy Erica Smith cita um exemplo da aplicação dessa perspectiva apocalíptica à política brasileira em um sermão de um pastor $\mathrm{AD}$ :

"O Brasil sempre acompanhou os Estados Unidos na luta contra o comunismo...Não aceitamos totalitarismo ou partidos totalitários. Aqui no Brasil tivemos a Revolução de 1964 [este é o termo do regime militar para seu golpe de 1964]. Quem fez a revolução era filiado ao PT, ao Partido Comunista, ao Partido Comunista do Brasil. Esses partidos podem mudar de nome, mas permanecem as mesmas. Eles não acreditam em Deus, eles não lutam contra a violência, eles não apoiam a legislação que apoia as famílias. Mas nada disso me surpreende...Essas coisas são sinais de que Jesus está voltando. Por isso não prego contra o PT. Eu sei que é a vontade de Deus que isso aconteça" (Smith 2019:84-5).

Este é um caso interessante de como a lógica apocalíptica leva, aparentemente, o pastor a uma passividade política. Ele implicitamente demoniza o Partido dos Trabalhadores, tratando-os como sinais do fim dos tempos, como expressões do mal que servem como instrumentos para a ação de Deus. Eles são simplesmente ateus que não apoiam famílias. As realidades políticas são apresentadas pelo pastor em termos totalmente dualistas, típicos do gênero apocalíptico, encontrados em vários livros do Novo Testamento. Os textos apocalípticos frequentemente apresentam o estado de coisas como uma representa- 
ção do mal e alertam o leitor para evitar qualquer compromisso com esta época maligna e as suas figuras. A lógica, porém, carrega consigo uma hostilidade inerente ao grande partido da esquerda, baseada em certos valores morais que são privilegiados e vistos como essenciais à vontade de Deus. Um deles é a 'legislação de apoio às famílias'.

Essa hostilidade, teologicamente fundamentada, ao Partido dos Trabalhadores é vista em Silas Malafaia, talvez o mais influente pastor pentecostal, em termos políticos, no Brasil. Malafaia lidera a congregação 'Assembleia de Deus Vitória em Cristo', no Rio de Janeiro, e está intensamente engajado na política do dia a dia, por meio de sua conta no Twitter. Tem 1,4 milhão de seguidores, três vezes mais que Edir Macedo.

Semelhante ao discurso neopentecostal, Malafaia vê a guerra espiritual ocorrendo na política brasileira. Ao contrário da tendência observada na IURD, no entanto, Malafaia não se abstém de aplicar as metáforas teológicas, que descrevem esta guerra espiritual em um nível mais geral, diretamente às realidades políticas mais específicas. Durante a campanha de 2018, Malafaia endossou, explicitamente, Bolsonaro como o candidato em que os verdadeiros evangélicos deveriam votar. Isso seguiu um padrão na atividade pública de Malafaia. Em 2010, ele havia endossado abertamente o principal opositor de Dilma Rousseff, José Serra, e, em 2014, ele apoiou a integrante da AD, Marina Silva, embora só depois dela ter retirado o apoio ao casamento gay e à criminalização da homofobia de seu programa de governo. Malafaia legitima seu partidarismo político nas eleições presidenciais com um dualismo cosmológico gritante entre o bem e o mal, Deus e o diabo. Nas rádios evangélicas do Rio de Janeiro era possível ouvir o pastor pentecostal interrogar o ouvinte com uma opção carregada de densidade teológica: "Você tem a mente de Cristo ou vai votar nessa gente que faz o jogo de satanás?". Com essas palavras, Malafaia confrontou os ouvintes de uma das rádios mais populares do Rio de Janeiro (Pacheco 2018). Quem acompanhou a ação política de Malafaia por algum tempo não ficou com dúvidas sobre quem eram 
as pessoas que "jogavam com o diabo". Afinal, muitos se lembram da demonização explícita de Malafaia da presidente e do seu partido quando buscaram a reeleição em 2014. Após a vitória de Dilma no primeiro turno, Malafaia afirmou que "O diabo inventou a mentira, Dilma e o PT aperfeiçoaram”.

Fundamental para o gênero apocalíptico é a ideia de que a mensagem de uma reviravolta radical é revelada a uma pessoa ou grupo eleito por Deus. Curiosamente, a primeira vez que Bolsonaro apareceu em público, depois que sua vitória eleitoral foi confirmada, ele foi à igreja de Malafaia. Bolsonaro aparentemente confessou que não era o mais capaz, mas afirmou que Deus dá poder aos eleitos ("Tenho certeza de que não sou o mais capacitado, mas Deus capacita os escolhidos"). Dessa forma, ele indiretamente se referiu a si mesmo como um eleito, o que é uma ideia teológica poderosa, particularmente na teologia pentecostal, que se baseia na autoridade carismática ao invés da institucional. No evento, Malafaia elaborou mais a ideia de eleição divina de Bolsonaro, e reforçou-a com a recitação de $1^{\circ}$ Coríntios (1:27-29) e a teologia da eleição de Paulo, que "Deus escolheu as coisas fracas do mundo para envergonhar as fortes" (1 Cor 1:27b). Em seguida, Malafaia foi mais longe, afirmando que "por isso Deus te escolheu”, apontando com o dedo para o Bolsonaro. ${ }^{6}$ Bolsonaro não fora escolhido apenas pela maioria dos brasileiros. Na visão de Malafaia, ele também foi escolhido por Deus.

Uma das principais razões pelas quais Malafaia deveria conceber Bolsonaro como preferido pelo próprio Deus é a própria razão pela qual ele apenas endossaria condicionalmente um candidato evangélico à presidência (Marina Silva) em 2014: O conservadorismo moral que caracteriza o pentecostalismo de inspiração mais clássica, principalmente centrada na questão da homossexualidade, nas palavras de pastores pentecostais como Malafaia, 'a ideologia de gênero'. Por se tratar de uma ideologia que ameaça a ordem divina do homem e da mulher como fundamento da família, o Brasil deve ser resgatado dela. Portanto, um tipo de salvação cristã está em questão, este sendo 
o evento principal neste drama cosmológico e que é interpretado de maneiras tão diversas em diferentes teologias cristãs, construídas em múltiplos contextos. E é aí que entra o catolicismo neoconservador.

\section{A justificativa teológica do antipetismo: catolicismo neoconservador}

De acordo com o Pew Research Center, o motivo mais frequentemente relatado pelos evangélicos norte-americanos para ter apoiado Donald Trump foi que "ele não é Hillary Clinton". A base eleitoral da direita cristã foi levada a apoiar Trump, em medida significativa por causa de sua oposição a seu oponente político. Um aspecto fundamental para a equivalente brasileira da direita cristã norte-americana é um discurso predominante de oposição ao Partido dos Trabalhadores, o PT, dando origem ao termo 'petismo'. Durante décadas, o PT funcionou como uma âncora para a esquerda política. Embora tenha se movido mais para o centro político, enquanto governava, suas iniciativas resultaram em uma expansão histórica dos direitos LGBT. Essas políticas levaram a mobilizações reacionárias da direita cristã, como visto no caso do pentecostalismo de Malafaia. Mas as mobilizações cristãs contra a esquerda política não se limitaram, de forma alguma, ao Evangelicalismo Carismático.

A postura oficial da Igreja Católica, nas eleições de 2018, foi apartidária e os pronunciamentos do presidente da Conferência Episcopal (CNBB), cardeal Sergio da Rocha, se restringiram a admoestações gerais para aconselhar o eleitor católico a apoiar candidatos a favor da democracia. O católico Bolsonaro, que havia sido batizado no rio Jordão por um pastor pentecostal e frequentava uma igreja batista, por sua vez, atacou a CNBB como 'a parte podre da Igreja' (Conti 2018). Em sua conta no Twitter, porém, Bolsonaro havia, em 2017, elogiado o canal no youtube do padre católico Paulo Ricardo. Ricardo não é uma autoridade formal na Igreja Católica, mas é respaldado pela rede de TV ligada à Renovação Carismática Católica. Ricardo ganhou publicidade por meio do uso de várias mídias (Silveira 2018). Ele tem 
mais de 1,4 milhão de seguidores no Facebook e oferece cursos online por meio de seu site. Seu conteúdo sinaliza afinidade com o discurso do ensaísta Olavo de Carvalho, em particular, no uso da categoria de 'marxismo cultural'.

Depois que Bolsonaro foi esfaqueado, em um comício de campanha, em setembro de 2018, Ricardo fez um sermão que foi difundido nas redes sociais, onde ele falou sobre perseguição moral e aludiu ao esfaqueamento de Bolsonaro (Balloussier 2018a). Ao contrário de Malafaia, Ricardo se recusou a endossar abertamente qualquer candidato político. Ao manter sua postura apartidária, ele se refere à autoridade do ex-papa Bento XVI, em vez do papa atual, um padrão em sua política interpretativa. Ricardo faz parte de setores do clero que, como identificou Amy Erica Smith, se opõem fortemente ao PT, mas nem sempre foram partidários fervorosos dos candidatos da oposição (2019:85).

No entanto, padre Paulo Ricardo é um exemplo claro, e poderoso, do componente católico da guerra cultural. É um padre influente, que propaga uma cosmovisão que considera verdadeiramente católica e incompatível com aquela que denuncia como o 'marxismo cultural' da esquerda brasileira. Ele normalmente apresenta seu adversário de esquerda em termos de oposição total. Segundo Ricardo, enquanto seu catolicismo dissemina a verdade, o revolucionário de esquerda nem mesmo acredita na existência da verdade. Além disso, o marxismo cultural é um fenômeno global que, desde os dias em que Engels via a família como a origem das desigualdades sociais, se propõe a destruir a família tradicional. Para Ricardo, existe uma genealogia ideológica que começa com Marx e Engels e leva, na atualidade, até às Nações Unidas e às ONGs. Portanto, é uma ameaça global à vida familiar cristã dos fiéis brasileiros. $\mathrm{O}$ marxismo cultural é uma força por meio de iniciativas políticas do Partido dos Trabalhadores, mas também entrou na Igreja Católica por meio da teologia da libertação, fruto de uma estratégia marxista. Como o marxismo não conseguiu erradicar a religião por meio da Revolução Russa, os gulags e a Guerra 
Civil Espanhola, empregaram uma nova tática: infiltrar-se na Igreja com o objetivo de destruí-la por dentro. Com a imagem de Leonardo Boff em seu site, Ricardo afirma que a teologia da libertação nega a transcendência, uma crítica que se assemelha àquela pelo Vaticano à Teologia da Libertação, formulada pelo cardeal Ratzinger na década de 1980, para a Congregação da Doutrina da Fé, possivelmente uma das fontes de autoridade oficial para Ricardo. Desta forma, o adversário religioso na guerra cultural de Ricardo está dentro e fora da Igreja Católica.

Sua teologia é livre do evangelho da prosperidade e marcadamente menos apocalíptica na medida em que ele constrói, seletivamente, uma visão da história humana, na qual reivindicações progressivas por minorias sexuais tornam-se expressões de um marxismo cultural que visa destruir completamente o cristianismo. Consequentemente, não pode haver compromissos com essas forças culturais destrutivas com ramificações globais. Ele compartilha as preocupações morais do conservadorismo pentecostal e tem defendido uma aliança estratégica com eles. Em um tom menos diretamente político, e notavelmente mais intelectual, Ricardo tornou-se um grande símbolo de um neoconservadorismo católico que só é compartilhado por uma minoria de bispos, como o bispo Dom Orani Tempesta. Mesmo assim, quando Ricardo ataca ferozmente a esquerda brasileira, por suas tentativas de desmantelar a família tradicional por meio de novos planos de educação sexual nas escolas primárias, ele pode valer-se do discurso católico oficial que alerta contra a chamada 'ideologia de gênero'. Indiscutivelmente, o primeiro documento eclesial da Igreja Católica na América Latina que empregou a expressão foi um documento de 1998 da Conferência Episcopal do Peru (Coelho Santos 2016). O termo foi reconhecido como válido para a teologia católica na Conferência dos Bispos da América Latina em Aparecida, em 2007, e a advertência contra a ideologia foi reiterada na exortação apostólica do Papa Francisco 'Amoris Laetitia' (\$ 56) de 2016. Sua denúncia teológica é comum na América Latina, tanto entre protestantes quanto entre católicos. 


\section{A direita cristã: autoritária ou democrática?}

A direita cristã no Brasil tem se mobilizado contra a aceleração de políticas progressistas, especialmente no que diz respeito aos direitos legais das minorias sexuais. Em termos de reconquista do poder eleitoral, tiveram grandes vitórias, culminando recentemente com a presidência de Jair Bolsonaro. Além disso, enquanto a direita cristã nos Estados Unidos, há décadas, lutou para derrubar a decisão Roe vs. Wade, a contraparte brasileira pode confiar confortavelmente no status quo restritivo da legislação sobre o aborto. Isso constitui uma grande diferença. No entanto, os paralelos existem.

Novas autoridades surgiram na paisagem religiosa, em mudança do Brasil. Silas Malafaia e o padre Paulo Ricardo podem ser considerados figuras carismáticas com uma influência política que, em parte, foi possibilitada pelo ciberativismo. Além disso, não é a liderança formal da Igreja Católica que mobilizou os eleitores para eleger políticos de direita nas últimas eleições. Longe disso, os bispos católicos são vistos por muitos na direita como uma ameaça política, em questões como ecologia, direitos dos trabalhadores e o legado da esquerda.

Por um lado, a direita cristã pode ser considerada uma contribuição para a democracia. Em vez de algum tipo de manipulação do voto religioso ou controle do cérebro, o ativismo religioso fomenta a mobilização, polêmica e discussões em vários níveis da sociedade. O fato de uma minoria religiosa, como os pentecostais, não ter sido sub-representada no Congresso é uma conquista da democracia brasileira. Smith descobriu que o clero apoia mais a democracia representativa do que seus fiéis (2019:172). Para a democracia brasileira, a diminuição do seu apoio entre as pessoas comuns é preocupante. À luz do papel proeminente da religião na política brasileira, no entanto, a crença firme na democracia entre os líderes religiosos é um sinal saudável. Além disso, a infraestrutura dessas comunidades cristãs, de rápido crescimento, tem permitido uma mobilidade social de segmentos da sociedade que, de outra forma, teriam poucas chances em um sistema eleitoral onde a disputa por cargos públicos tem altos custos 
econômicos. Enquanto a esquerda católica, nos anos setenta e oitenta do século passado, provou ser uma força maior a favor da democracia por causa da sua resistência ao regime militar e pelo fomento de uma nova cultura cívica no Brasil, a direita cristã dos anos iniciais desse século constitui um fenômeno da democracia.

Por outro lado, devem ser observados os traços autoritários de algumas das teologias que operam na direita cristã. $\bigcirc$ raciocínio apocalíptico ou a demonização podem fomentar mobilizações políticas, mas não discussões deliberativas na democracia. Longe disso, a demonização dos oponentes políticos pela direita cristã anda de mãos dadas com um ciberativismo que espalha desinformação e ódio, ao invés de deliberações políticas esclarecedoras. Conforme observado por Martin Lindhardt, as habilidades organizacionais e retóricas adquiridas nas práticas pentecostais na América Latina não são automaticamente traduzidas em culturas democráticas e diálogo político na região (Lindhardt 2013). Existem potencialidades autoritárias no cristianismo que foram atualizados por meio dessa força religiosa da direita política, e eles efetivamente apoiaram um candidato que defendeu as violações dos Direitos Humanos do regime militar (1964-1985). Além disso, pode-se dizer que as políticas conduzidas em nome da ideologia de gênero levam a desvalorizações contínuas da liberdade política no campo dos direitos reprodutivos. No mínimo, a valorização do poder do Estado pela direita cristã para fins morais específicos, está em potencial tensão com a cultura liberal da democracia constitucional. Mas, dada a força penetrante da religião no Brasil, os envolvidos na religião podem ser, de fato, a chave para a preservação da democracia liberal. Nas palavras de Amy Erica Smith:

"As normas seculares levam os cidadãos a resistir parcialmente à influência do clero, ao ativismo político e aumentam a legitimidade da democracia e do sistema político. Se os conflitos ideológicos, eleitorais e sociais são os sintomas das guerras culturais brasileiras, as normas seculares - mesmo, ou principalmente, as normas seculares de cidadãos altamente religiosos - são a cura potencial" (Smith 2019:145). 
* Nota dos Editores: Esta é uma tradução do artigo original "The Political Conditions and Theological Foundations of the New Christian Right in Brazil”, publicado em 2020 no periódico Iberoamericana - Nordic Journal of Latin American and Caribbean Studies, 49(1):63-73. Agradecemos ao autor a gentileza de autorizar a publicação desta versão em português.

\section{Notas:}

1 Em uma pesquisa realizada pelo Pew Research Center em 2006, nada menos que $79 \%$ concordaram com a opinião de que o aborto nunca é justificável (Machado 2012:37).

2 De acordo com as tipologias de Ricardo Mariano (1999).

3 A instrução religiosa confessional é comumente considerada como ilegal, embora a concordata de 2009 com o Vaticano contém certas ambiguidades a respeito desta questão (Cunha 2009).

4 Benedita da Silva tem uma trajetória atípica como política pentecostal no Brasil. (Corten 1996:241-252).

5 https://www.youtube.com/watch?v=krcFLKZK9ik. Acessado em 27/06/19.

6 https://www.youtube.com/watch?v=y2nZ1HDT450. Acessado em 27/06/19.

\section{Referências:}

ABRANCHES, S. et al. 2019. Democracia em risco? 22 ensaios sobre o Brasil hoje. São Paulo: Companhia das Letras.

ALMEIDA, R. D. 2019. "Bolsonaro Presidente: Conservadorismo, evangelismo e a crise brasileira”. Novos estudos CEBRAP, 38(1):185-213. . 2020. "The broken wave: Evangelicals and conservatism in the Brazilian crisis". HAU journal of ethnographic theory, 10(1):32-40.

ARAÚJO, E. 2019. "Agora Falamas”. (http://funag.gov.br/images/2020/ NovaPoliticaExterna/71_agora_falamos.pdf.; acesso em 01/07/2021).

BALLOUSSIER, A. V. 2018a. "Padre anti-PT cita facada em Bolsonaro ao falar em "perseguição moral'”. Folha de São Paulo 14.09.18.

2018b. "Universal usou sua máquina para exaltar Bolsonaro e atacar Haddad”. Folha de São Paulo 01.11.18.

BBC. 2018. "Jair Bolsonaro beyond the sound bites: What are his policies?" (https://www. bbc.com/news/world-latin-america-45982501; acesso em 28/10/18).

BIRMAN, P. \&LEHMANN, D. 1999. Religion and the Media in a Battle for Ideological Hegemony: The Universal Church of the Kingdom of God and TV Globo in Brazil. Bulletin of Latin American Research, 18(2): 145-164. 
BOLSONARO, J. M. 2019. "Discurso do Presidente da República, Jair Bolsonaro, durante Cerimônia de Posse no Congresso Nacional". (http:// www2. planalto.gov.br/acompanhe-o-planalto/ discursos/2019/discurso-dopresidente-da-repub-lica-jair-bolsonaro-durante-cerimonia-de-posse-nocongresso-nacional; acesso em 06/11/2019).

BOWLER, K. 2013. Blessed: A History of the American Prosperity Gospel. New York: Oxford University Press.

BROWN, W. 2006. "American Nightmare: Neoliberalism, Neoconservatism, and De-Democratization". Political Theory, 34(6):690-714.

CARRANZA, B. 2020. "Apresentação - Erosão das democracias latinoamericanas: A ascensão política dos cristãos”. Ciencias Sociales y Religión, 22:1-17.

COELHO, F. \& SANTOS, N. 2016. "A mobilizacão católica contra a "ideologia de gênero" nas tramitacões do plano nacional de educação brasileiro". Religare, 13(1):27-48

CONTI, MS. 2018. "Mentiras cavalares e militares". (https://www1.folha.uol.com. $\mathrm{br} /$ colunas/mariosergioconti/2018/10/mentiras-cava-lares-e-militares.shtml; acesso em 20/10/18).

CORTEN, A. 1996. Os Pobres e o Espírito Santo: O Pentecostalismo no Brasil. Petrópolis: Vozes.

CUNHA, L. A. 2009. "A educação na concordata Brasil-Vaticano”. Educação $\mathcal{E}$ Sociedade, 30(106):263280.

DA SILVA, L. I. L. 2003. "Pronunciamento do Presidente da República, Luiz Inácio Lula da Silva, na sessão solene de posse no Congresso Nacional”. (http://www.biblioteca.presiden-cia.gov.br/presidencia/ex-presidentes/ luiz-ina-cio-lula-da-silva/discursos/discursos-de-posse/ discurso-de-posse-1omandato/view.; acesso em 06/11/2019).

DATAFOLHA. 2018. "Intenção de voto para presidente da República 25/10/18”. (http:// media.folha.uol.com.br/datafolha/2018/10/26/34 16374d208f7def05d1476d05ede73e.pdf.; acesso em 01/07/2021).

FOLLMANN, J. I. 2000. "Progressive Catholicism and Left-Wing Party Politics in Brazil”. In: HEWITT, W. E. \& BURDICK, J. (eds.): The Church at the grassroots in Latin America: perspectives on thirty years of activ-ism, pp. 53-68. Westport: Praeger..

FRESTON, P. 2001. Evangelicals and politics in Asia, Africa, and Latin America. Cambridge: Cambridge University Press. 2013. "Pentecostals and Politics in Latin America". In: MILLER, D. E., Flory, R. W. \& Sargeant, K. H. (eds.): Spirit and Power: The Growth and Global Impact of Pentecostalism, pp.101-118. Oxford: Oxford University Press.

GARRARD-BURNETT, V. 2013. "Neo-pentecostalism and Prosperity Theology in Latin America: A Religion for Late Capitalist Society”. Iberoamericana: Nordic Journal of Latin American and Caribbean Studies, 42(1-2):21-34.

GENTILE, E. 2006. Politics as religion. Princeton: Princeton University Press. 
KURU, A. T. 2007. "Passive and assertive secularism: Historical conditions, ideological struggles, and state policies toward religion”. World Politics, 59(4):568-594.

LACERDA, F. 2018. "Assessing the Strength of Pentecostal Churches Electoral Support: Evidence from Brazil". Journal of Politics in Latin America, 10(2):3-40.

LEHMANN, D. 2013. "Religion as heritage, religion as belief: Shifting frontiers of secularism in Europe, the USA and Brazil". International Sociology, 28(6):645662.

LEVINE, D. H. 2012. Politics, religion $\mathcal{E}$ society in Latin America. Boulder: Lynne Rienner Publications.

LINDHARDT, M. 2013. "Pentecostalism and Politics in Neoliberal Chile". Iberoamericana Nordic Journal of Latin American and Caribbean Studies, 42(12):59.

LØLAND, O. J. 2015. "The Position of the Biblical Canon in Brazil: From Catholic Rediscovery to Neo-Pentecostal Marginalisation". Studies in WorldChristianity, 21(2):98-118.

MACEDO, E. 2012. "Desabafo da Revolta". (https://blogs.universal.org/ bispomacedo/ 2012/10/03/desabafo-da-revolta/; acesso em 01/07/2021)

MACHADO, M. D. 2012. "Religião, cultura e política". Religião E⿱ Sociedade, 32(2):29-56.

MAINWARING, S. 2018. "The uneven institutionalization of a party system: Brazil”. In MAINWARING, S. (ed.): Party systems in Latin America: institutionalization, decay, and collapse, pp. 164-197. Cambridge: Cambridge University Press.

MARIANO, R. 1999. Neopentecostais: Sociologia do novo pentecostalismo no Brasil. São Paulo: Edições Loyola.

2011. "Laicidade à brasileira: Católicos, pentecostais e laicos em disputa na esfera pública". Civitas - Revista de Ciências Sociais, 11(2):238-258.

MARIANO, R. \& ORO, A. P. 2017. "Religion and Politics in Brazil". In SCHMIDT, B. E. \& ENGLER, S. (eds.): Handbook of con-temporary religions in Brazil, pp. 363-378. Leiden: Brill.

MARTÍN, M. 2016. "Deus derruba a presidenta do Brasil". El Pais. (https://brasil. elpais.com/ brasil/2016/04/18/politica/1460935957_433496. html.; acesso em 01/07/2021).

MILLIES, S. P. 2018. Good intentions: a history of Catholic voters' road from Roe to Trump. Collegeville: Liturgical Press.

MORA, G. C. 2008. "Marketing the 'health and wealth gospel' across national borders: Evidence from Brazil and the United States". Poetics, 36(5):404-420.

ORO, A. P. 2003. "A política da Igreja Universal e seus reflexos nos campos religioso e político brasileiros". Revista Brasileira de Ciências Sociais, 18(53):53-69.

PACHECO, R. 2018. Um mergulho na pregação de Silas Malafaia contra o PT e a favor de Bolsonaro numa rádio evangélica. 26.10.18. 
PAZ, E. M. 2018. "Party funding in Brazil following the redemocratization: A brief critical overview". In MENDILOW, J. \& PHELIPPEAU, E. (eds.): Handbook of political party funding. pp. 386-396. Cheltenham: Edward Elgar.

PEW RESEARCH CENTER. 2014. "Religion in Latin America: Widespread Change in a Historically Catholic Region". (http://www.pewforum.org/ 2014/11/13/religion-in-latin-america/; acesso em 01/07/2021).

REICH, G \& DOS SANTOS, P. 2013. "The Rise (and Frequent Fall) of Evangelical Politicians: Organization, Theology, and Church Politics". Latin American Politics and Society, 55(4):1-22.

SANTOS, G. 2018. "Por que política se o Reino é de Deus?" (https://blogs. universal. org/bispomacedo/2018/10/15/por-que-politica-se-o-reino-e-dedeus/; acesso em 01/07/2021).

SCHMIDT, B. E. \& ENGLER, S. 2017. "Introduction". In SCHMIDT, B. E. \& ENGLER, S. (eds.): Handbook of con-temporary religions in Brazil, pp. 1-31. Leiden: Brill.

SHAH, T. S. 2004. "The Bible and the Ballot Box: Evangelicals and Democracy in the 'Global South'”. SAIS Review, 24(2):117-132.

SILVEIRA, E. J. 2018. "Tradicionalismo católico e espaço público. A guerra cultural dos clérigos ultraconservadores". Revista Éclesiástica Brasileira, 75(300):935-957.

SMITH, A. E. 2019. Religion and Brazilian democracy: mobilizing the people of God. Cambridge: Cambridge University Press.

STÅLSETT, S. J. 2006. "Offering on-time deliverance: The pathos of NeoPentecostalism and the spirits of globalization". In STÁLSETT, S. J. (ed.): Spirits of globalization: the growth of Pentecostalism and experiential spiritualities in a global age, pp. 198-212. London: SCM Press.

TAYLOR, S. L. 2017. "Electoral systems in context: United States". In HERRON, E. S., PEKKANEN, R. \& SHUGART, M. S. (eds.): The Oxford handbook of electoral systems Oxford handbooks online, pp. 722-739. New York: Oxford University Press.

VRIES, H. D. 2006. "Introduction". In VRIES, H. D. \& SULLIVAN, L. E. (eds.): Political Theologies: Public Religions in a Post-Secular World, pp. 1-88. New York: Fordham University Press.

The Political Conditions and Theological Foundations of the New Christian Right in Brazil
Abstract: Jair Messias Bolsonaro won the 2018 presidential elections in Brazil with the support of nearly $70 \%$ of the Evangelicals and around $50 \%$ of the Catholics in the country. This article aims at exploring some of the politically influential theologies disseminated by some of Bolsonaro's religious allies by constructing 
three theological typologies: Neoliberal supernaturalism, apocalyptic dualism and neoconservative Catholicism. These theological ideas gain relevance through an alliance between religious groups and the political right that based on the movement's key issues and cultural conditions is comparable to the Christian Right in the United States. The rise of Bolsonaro and the turn to the right in Brazilian politics can partly be understood as an effect legitimated by this new political alliance of three politically conservative Christian forces and their theologies: traditional Pentecostalism, neo-Pentecostalism and neoconservative Catholicism. Although there are authoritarian traits within what can be labelled Brazil's new Christian Right, this political phenomenon can also be said to contribute to Brazilian democracy.

Keywords: Brazilian religion, Secularism, Prosperity gospel, Catholic neoconservatism, Pentecostalism, Political theology.

Tradução: Sandro Soares de Freitas.

Revisão Técnica: Edwin B. Reesink.

Recebido em julho de 2021.

Aprovado em agosto de 2021. 